\title{
Is Computer Science Dying?
}

\section{Alex Nicolau}

UC Irvine

This seminar was jointly organized with the High Performance Computing research group (CAP) of the Computer Architecture Department at UPC.

\section{Abstract}

This talk surveys the state of Computer Science as an academic discipline. It reviews some positive and some less positive trends, and attempts to identify and discuss some things that we, as an academic community, could do better. To concretely illustrate our points, we discuss some case studies from some current/recent research projects that the author is involved in.

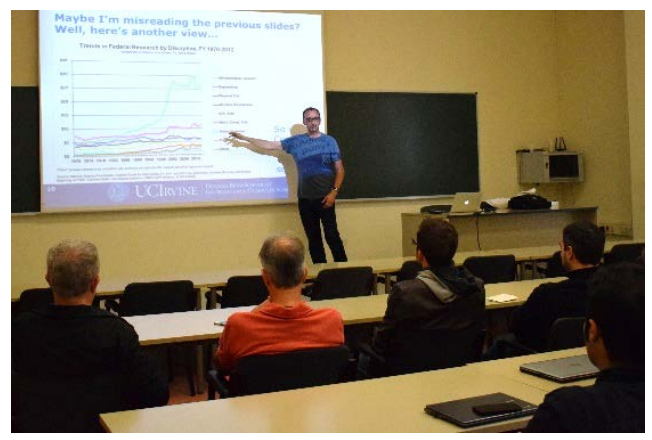

\section{Short bio}

Alex Nicolau is a professor and department chair of Computer Science at UC Irvine. A pioneer in Instruction Level Parallelism, and the application of ILP technology to CAD/Synthesis, his 28 Ph.D. graduates work/worked for high-tech companies such as Intel, Google, Yahoo, Qualcomm, and universities such as Stanford, UIUC, McGill, IIT Delhi. His more recent work centered on Embedded Systems and Synthesis, especially in performance/power tradeoffs, and performance issues in GPUs, FPGAs and HPC.

The author of well over 300 conference and journal articles plus many books, Alex is an IEEE Fellow and editor in chief of the International Journal of Parallel Programming, the oldest journal in that field. 